\title{
2.10 A MODEL SYSTEM FOR THE ASSESSMENT OF AMBIENT AIR QUALITY CONFORMING TO EC DIRECTIVES
}

\author{
Alfred Trukenmüller, K. Heinke Schlünzen, David Grawe \\ Meteorological Institute, Centre for Marine and Climate Research, University of Hamburg, \\ Germany
}

\section{INTRODUCTION}

According to the EC framework and daughter directives (European Community, 1996, 1999, 2000, 2002), ambient air quality must be assessed throughout the territory of member states. Concentrations shall be established at scales representative for 'at least $1000 \mathrm{~km}^{2}$, , but also for 'several square kilometres' and for 'no less than $200 \mathrm{~m}^{2}$, Limit values refer to, e.g., annual mean values or the number of exceedances for 24-hour and 1-hour average concentrations. Under certain conditions modelling techniques can be used. Since no reference techniques are specified different approaches may be considered. For the outlined purpose the model system M-SYS has been developed (Trukenmüller et al., 2004).

\section{METHOD}

The model system M-SYS (Figure 1) is based on the non-hydrostatic MEsoscale TRAnsportand Stream model METRAS (Schlünzen, 1990; Schlünzen et al., 1996), the obstacleresolving microscale model MITRAS (Schlünzen et al., 2003; Grawe et al., 2004), and the MEso- and Microscale Chemistry-Transport-Models MECTM (Müller et al., 2000, Lenz et al., 2000) and MICTM (Grawe, 2004). The two microscale models are based on the mesoscale models with respect to the equations solved, approximations and parameterisations used and the numerical schemes applied. However, the microscale models explicitly treat obstacles and are thus applicable to simulate flow fields and dispersion within the obstacle layer. All in all consistent models for the simulation of flow, transport and chemistry are used on the mesoscale and the microscale.

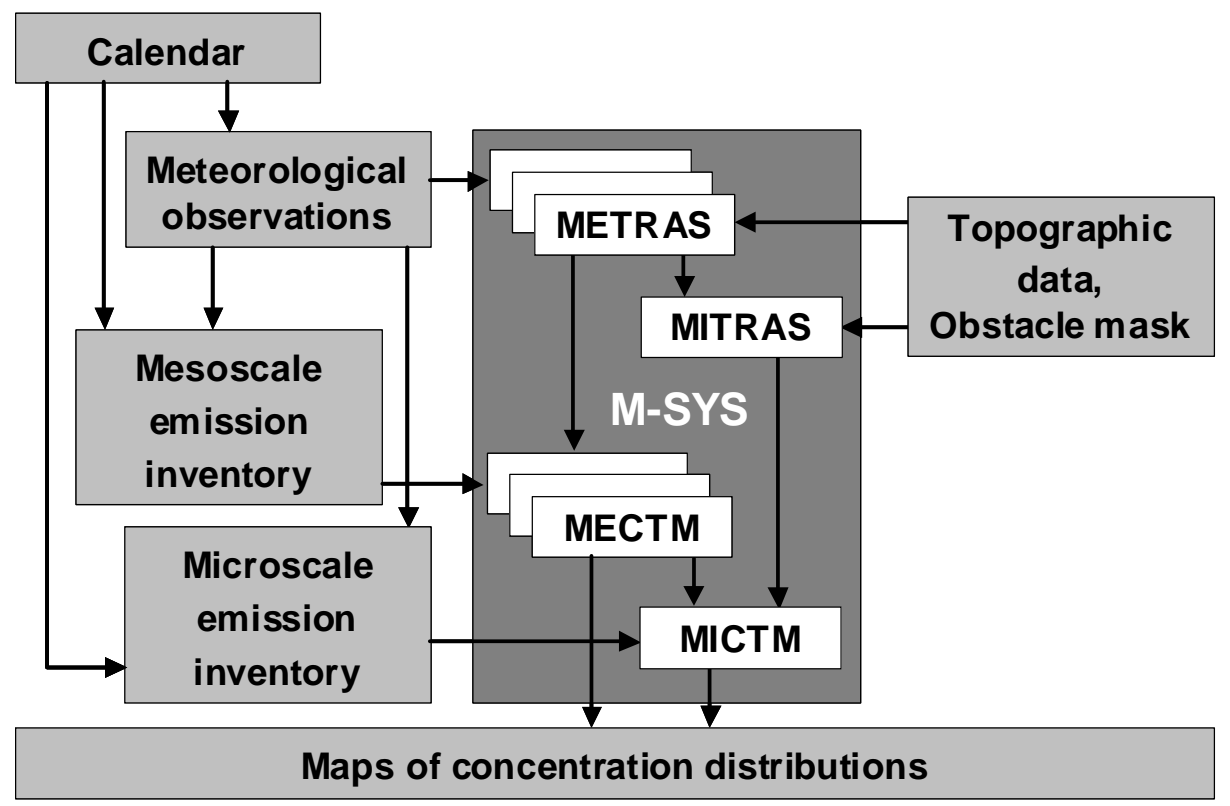

Figure 1. Structure of the model system M-SYS. 
Three nested model areas were implemented in the mesoscale. This model hierarchy covers north-west Europe (outermost model area), the German federal state of Lower Saxony (intermediate model area) and the agglomeration Hanover-Brunswick (innermost model area). Within this innermost mesoscale model that uses a resolution of $1 \mathrm{~km}$, one column $(1 \mathrm{~km}$ by 1 $\mathrm{km}$ area) in the agglomeration of Hanover is simulated in the microscale model. The column is centred at Göttinger Straße in Hanover, an area that has intensely been investigated in the BMBF-funded project VALIUM by field (Schäfer et al., 2004) and wind tunnel experiments (Pascheke et al., 2002).

\section{RESULTS}

The results of the mesoscale model for the outermost model domain have been compared to DWD routine surface observations in the area of Lower Saxony. The comparison is based on the concept of hit rates (Schlünzen and Katzfey, 2003). They describe the percentage of model results within a prescribed accuracy to observations at the same place and time. The desired accuracy is taken from Cox et al. (1998) for the meteorological data. The METRAS hit rates (Table 1) are as high or even higher than the best 12-hour forecast of Cox et al. (1998). The agreement of the measured and simulated meteorological data is a precondition for a correct simulation of pollutant concentrations.

Table 1. Average hit rates for meteorological values in the M-SYS outermost model domain (grid spacing $16 \mathrm{~km}, 10$ runs) and for 12-hour forecasts in a comparison by Cox et al. (1998) (grid spacing $46 \mathrm{~km}, 60$ runs).

\begin{tabular}{ccccc}
\hline \multirow{2}{*}{ Parameter } & \multirow{2}{*}{ Accuracy desired } & \multicolumn{3}{c}{ Surface predictions within criteria } \\
& M-SYS & Cox et al. (best) & Cox et al. (mean) \\
\hline Temperature & $\pm 2{ }^{\circ} \mathrm{C}$ & $58 \%$ & $42 \%$ & $35 \%$ \\
\hline $\begin{array}{c}\text { Dew point } \\
\text { temperature }\end{array}$ & $\pm 2{ }^{\circ} \mathrm{C}$ & $64 \%$ & $40 \%$ & $35 \%$ \\
\hline Wind speed & $\pm 1 \mathrm{~m} \mathrm{~s}-1$ & $51 \%$ & $41 \%$ & $31 \%$ \\
\hline Wind direction & $\pm 30^{\circ}$ & $44 \%$ & $40 \%$ & $38 \%$ \\
\hline
\end{tabular}

For chemical concentrations, accuracy requirements are defined in the daughter directives:

- For sulphur dioxide $\left(\mathrm{SO}_{2}\right)$ the maximum deviation of the measured and calculated concentration levels must not exceed $50-60 \%$ of the hourly limit value $\left(350 \mu \mathrm{g} \mathrm{m}^{-3}\right)$,

- For nitrogen dioxide $\left(\mathrm{NO}_{\mathrm{x}}\right)$ the maximum deviation of the measured and calculated concentration levels must not exceed 50-60\% of the hourly limit value $\left(250 \mu \mathrm{g} \mathrm{m}^{-3}\right)$,

- For ozone $\left(\mathrm{O}_{3}\right)$ the maximum deviation of the measured and calculated concentration levels must not exceed $50 \%$ of the hourly threshold value $\left(180 \mu \mathrm{g} \mathrm{m}^{-3}\right.$; this value is the information threshold value).

For a total of 40 days of year 2000, concentrations modelled with M-SYS on the $16 \mathrm{~km}$ grid have been compared with measurements at seven NLÖ monitoring sites. All modelled concentrations of sulphur dioxide and nitrogen dioxide, giving a hit rate of $100 \%$ for this two pollutants. This fulfils the demands of the EC directives. For ozone the hit rate is slightly lower $\left(97 \%\right.$, based on the information threshold). Using the alert threshold $\left(240 \mu \mathrm{g} \mathrm{m}^{-3}\right)$ the hit rate is again $100 \%$. Thus, already the coarse resolution delivers quite reliable model results.

Maps for the urban background scale need a higher resolution than $16 \mathrm{~km}$ and thus the innermost model results are needed. For the maps with a resolution of $200 \mathrm{~m}^{2}$, which shall represent the air quality within the urban area, the obstacle resolving models 
MITRAS/MICTM are necessary. The mesoscale models METRAS/MECTM are nested twice into the outermost model area; and profiles calculated on the innermost mesoscale model for the inner area of Hanover are eventually used to initialise the obstacle resolving microscale models MITRAS and MICTM. To ensure reliability of the flow fields, MITRAS has been evaluated in comparison with wind tunnel data (Grawe et al., 2004).

Typical results of a simulation with the microscale models MITRAS/MICTM for the area of Göttinger Straße can be seen in Fig. 2. The figure shows the concentrations of nitrogen dioxide for $11^{\text {th }}$ April 2003, 7.00-7:30 CET in a selected part of the model domain. The approaching flow is from the lower left corner of the figure. Emissions originate predominantly from the four traffic lines parallel to the central street canyon, but also from neighbouring main and back streets within the whole model domain $\left(1 \times 1 \mathrm{~km}^{2}\right)$. Figure $2 \mathrm{a}$ illustrates the heterogeneous distribution of the pollutants within both, the central street canyon, the neighbouring streets and the backyards.

(a)

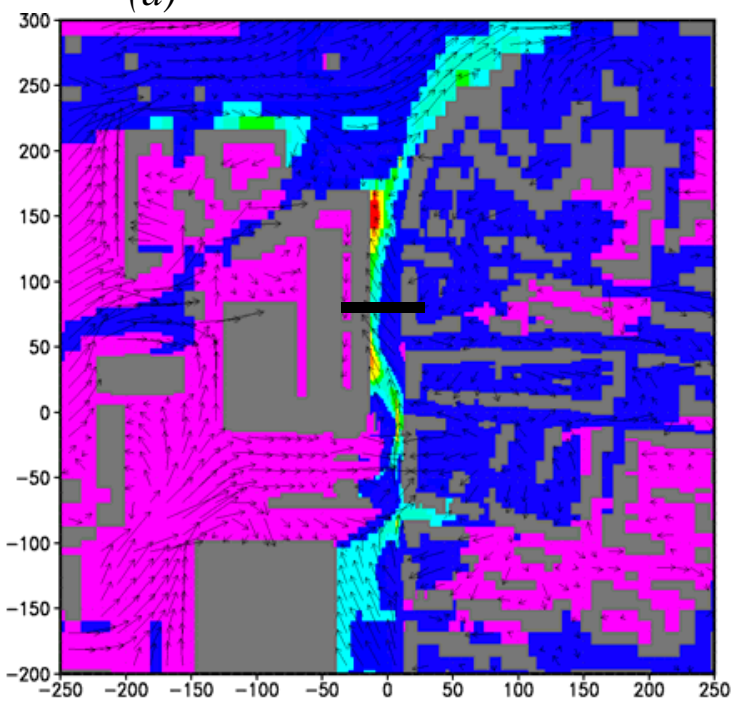

(b)

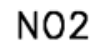

[ug/m3]

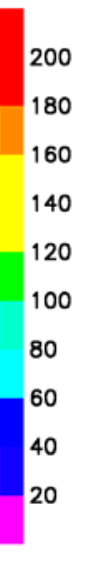

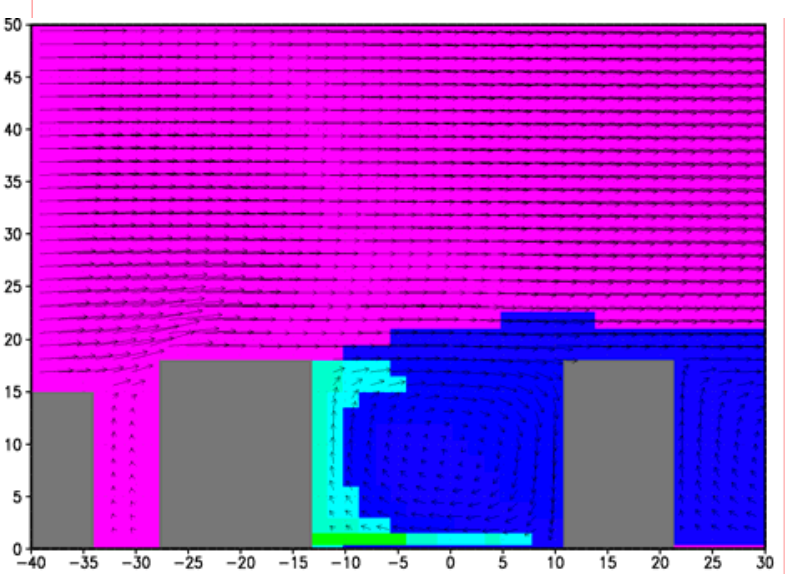

Figure 2. $\mathrm{NO}_{2}$ concentration for 11th April, 2003, 07:00-07:30.

(a) Horizontal cross section at $1.5 \mathrm{~m}$ above ground.

(b) Vertical cross section in the area denoted by a bar in the horizontal cross section.

Two distinct concentration maximums are found at the westward side of the central street canyon, while comparatively low concentration values appear on the eastward side. The distribution is strongly affected by the building structure, due to its influence on the simulated wind field. The spatial representativeness of concentration measurements within the area is very low not only for the wind field (Schlünzen et al., 2003), but also for the concentration field. Figure $2 \mathrm{~b}$ demonstrates the three-dimensionality of the pollutant transport in the obstacle layer. Emissions originating from traffic are transported above roof level towards backyard areas.

A comparison of MICTM model results with field measurements (Schäfer et al., 2004) shows that differences are all well within a factor of 2 of the measured data (Figure 3); most differences are within $50 \%$ of the measurements. Considering the heterogeneity of the flow and concentration fields (Figure 2a), the uncertainty of the emission data and that the comparison is made for one single case only the agreement is surprisingly high. It might be derived from this case that the $\mathrm{NO}_{2}$-fraction of $15 \%$ of the total $\mathrm{NO}_{\mathrm{x}}$ emissions, which is used in these simulations, might be too small, since a systematic underestimation is found for $\mathrm{NO}_{2}$ while NO is slightly overestimated from the model at all sites. At the same time $\mathrm{NO}_{\mathrm{x}}$ values 
are quite well simulated at all sites. This suggests that the overall traffic emissions are well prescribed.

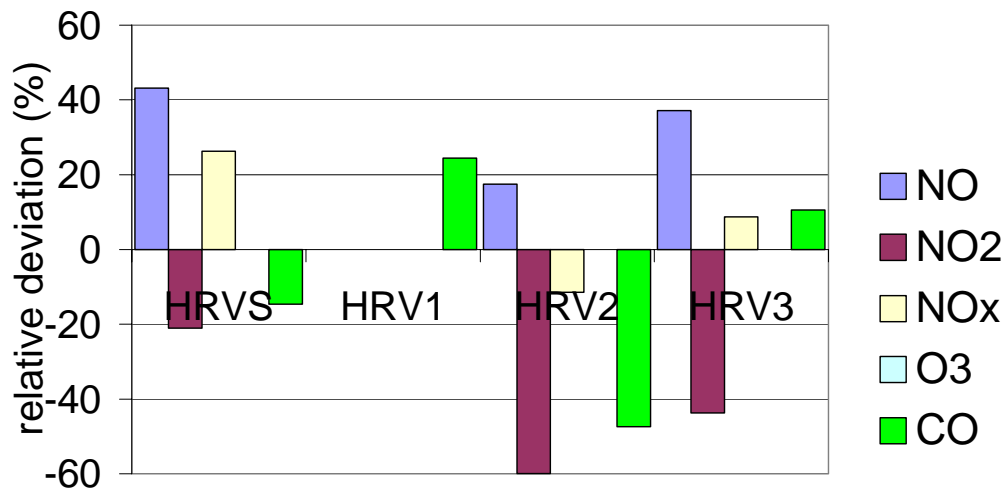

Figure 3. Comparison of simulated concentrations and field measurements within the street canyon Göttinger Straße, Hanover (11.04.03, 07:00-7:30). O3 was not measured at the selected street canyon measurement sites.

\section{CONCLUSIONS}

A multi-scale hierarchy of comprehensive models is required to reliably simulate concentrations in situations where no observations are available. Then the new approach foreseen by the directives to assess air quality from emission inventories and modelling can be applied. The model hierarchy M-SYS developed for this purpose is well applicable to simulate concentrations on different scales and with different resolutions. Comparisons with measured data show a quite good model performance, allowing to apply the model system to other regions and time periods as well. A drawback is the large amount of computer time and storage needed by the model system. Optimisation is thus necessary in order to use the model system on a routine basis. In addition, the preparation of input and comparison data needs to be simplified to reduce the amount of human power necessary for these simulations.

\section{ACKNOWLEDGEMENTS}

The authors would like to thank the German Federal Ministry for Education and Research for funding this project within AFO2000 under grant 07ATF12 (project VALIUM). The model simulations were made on the DKRZ vector computers within the University of Hamburg contingent. The British Atmospheric Data Centre kindly provided radiosonde data and sea surface temperatures, which were used as boundary conditions of the outermost model area. We thank the German weather service DWD for providing meteorological comparison data and the Lower Saxony State Agency for Ecology (NLÖ) for the concentration measurements. Emission data on all model scales were kindly provided by Jörg Kühlwein and Petra Blank of IER, University of Stuttgart, Germany.

\section{REFERENCES}

European Communities, 1996: Council directive 96/62/EC of 27 September 1996 on ambient air quality assessment and management. Official Journal of the European Communities, 21.11.1996, L 296/55-63.

European Communities, 1999: Council directive 1999/30/EC of 22 April 1999 relating to limit values for sulphur dioxide, nitrogen dioxide and oxides of nitrogen, particulate matter and lead in ambient air. Official Journal of the European Communities, 29.6.1999, L 163/41-60. 
European Communities, 2000: Directive 2000/69/EC of the European Parliament and of the Council of 16 November 2000 relating to limit values for benzene and carbon monoxide in ambient air. Official Journal of the European Communities, 13.12.2000, L 313/12-21.

European Communities, 2002: Directive 2002/3/EC of the European Parliament and of the Council of 12 February 2002 relating to ozone in ambient air. Official Journal of the European Communities, 9.3.2002, L 67/14-30.

Cox R., Bauer B.L. and Smith T., 1998: Mesoscale model intercomparison. Bull. Am. Met. Soc. 79, 265-283.

Grawe D, 2004: Verknüpfung von Modellen und Daten für die Konzentrationsvorhersage. $\mathrm{PhD}$ thesis, Faculty of Earth Sciences, University of Hamburg, in preparation.

Grawe, D, Schlünzen, K.H. and Pascheke, F., 2004: Comparison of results of an obstacle resolving numerical model with wind tunnel data. Poster 1,31 at 9th International Conference on Harmonisation within Atmospheric Dispersion Modelling for Regulatory Purposes, Garmisch-Partenkirchen, June 1-4, Germany.

Lenz C.-J., Müller F. and Schlünzen K.H., 2000: The sensitivity of mesoscale chemistry transport model results to boundary values. Env. Monitoring and Assessment, 65, 287 298.

Müller F., Schlünzen K.H. and Schatzmann M., 2000: Test of numerical solvers for chemical reaction mechanisms in 3D air quality models. Environmental Modelling Software, 15, 639-646.

Pascheke F., Leitl B. and Schatzmann M., 2002: High resolution validation data for urban type dispersion modelling. Presentation at the $8^{\text {th }}$ International Conference on Harmonisation within Atmospheric Dispersion Modelling for Regulatory Purposes, Sofia, October 14-17, Bulgaria.

Schäfer K., Emeis S, Hoffmann H, Jahn C, Müller WJ, Heits B, Haase D, Drunkenmölle W-D, Bächlin W, Leitl B, Pascheke F, Schlünzen KH and Schatzmann M, 2004: Field measurements within a quarter of a city including a street canyon to produce a validation data set. Presentation in Session 12 at 9th International Conference on Harmonisation within Atmospheric Dispersion Modelling for Regulatory Purposes, Garmisch-Partenkirchen, June 1-4, Germany.

Schlünzen K.H., 1990: Numerical studies on the inland penetration of sea breeze fronts at a coastline with tidally flooded mudflats. Beitr. Phys. Atmosph., 63, 243-256.

Schlünzen K.H., Bigalke K., Lüpkes C., Niemeier U. and von Salzen, K., 1996: Hints for using the mesoscale model 'METRAS'. Meteorologisches Institut, Universität Hamburg, METRAS Techn. Rep. 6, 52 S.

Schlünzen K.H., Hinneburg D., Knoth O., Lambrecht M., Leitl B., Lopez S., Lüpkes C., Panskus H., Renner E., Schatzmann M., Schoenemeyer T., Trepte S. and Wolke R., 2003: Flow and transport in the obstacle layer - First results of the microscale model MITRAS. J. Atmos. Chem., 44, 113-130.

Schlünzen K.H. and Katzfey J., 2003: Relevance of sub-grid-scale land-use effects for mesoscale models. Tellus, 55A, 232-246.

Trukenmüller A., Grawe D., Schlünzen K.H., 2004: A model system for the assessment of ambient air quality conforming to EC directives. Meteorologische Zeitschrift, in print. 